\title{
Functional Analysis of exhaust gas turbocharger regulator Jicheng $\mathrm{Yu}^{1, \mathrm{a}}$ \\ ${ }^{1}$ Eastern Liaoning University, Dandong, Liaoning, 118003, China \\ a email: yjc833@163.com
}

Keywords: gas regulator, turbocharger, the impeller speed, exhaust gas control

\begin{abstract}
The method of controlling exhaust gas uses cross-section controller to increases the rotational speed of the turbine or uses composite pressurized way to improve working conditions at low engine supercharger requirmente. Through analysising the exhaust gas flow path of the working chamber casing airflow change, uses exhaust gas flow rate adjusting means and the direction of the turbine inlet. Gas kinetic energy and momentum can be increased to improve the speed of the turbine. Tapered control means may adjust the flow rate and direction of the turbine exhaust gas into the working chamber. Variable cross-section controller can realize to control the rotational speed of the output of the turbine shaft.
\end{abstract}

\section{Introduction}

Exhaust gas turbocharger increases the engine's intake air piston chamber by air compression. Exhaust gas turbocharger using exhaust engine emissions inertia momentum driven turbine rotation of the turbine room. Coaxial turbine impeller driven by the rotation.

After allowing pressurized air impeller feed the engine cylinders. Engine exhaust emission increases the rotational speed of the turbine increases. This time to increase the pressure and density of the air feeding the engine cylinders. The corresponding increase in the amount of fuel and engine speed. The engine output power increases accordingly.

Engine exhaust has a 800-1000 k temperature and pressure of exhaust through the exhaust pipe into the turbine nozzle ring shell. Because of the nozzle ring through the surface is gradually shrinking, exhaust pressure and temperature drop and flow rate increased, and exhaust gas kinetic energy increase. Exhaust gas flow in a certain impact the direction of the turbine, make its high-speed rotation. The higher exhaust gas pressure, temperature and speed, the faster the speed of the turbine.

Gas turbine and compressor impeller is connected on the same rotor shaft. The equal speed. This compressor impeller rotation inside the air inhaled compressor through the air filter. Air to jilt to high-speed rotating impeller impeller edge, increase the speed and pressure, and into the diffuser. The shape of the diffuser to import small export large. Airflow speed drop, pressure. Air flow through the annular compressor casing chamber of the section from small to large, air pressure to continue to improve. The compressed air through the intake pipe into the engine cylinder.

In the exhaust gas turbo system, there is no mechanical connection between the turbocharger and the engine. Exhaust gas turbocharger is through the flow of air and exhaust gas coupled with internal combustion engine, adjust themselves. The turbocharger and engine speed and the rotation speed there is no direct link, is the use of waste gas energy work. Most USES centrifugal exhaust gas turbocharger compressor. Its export pressure can reach 140-300 kpa, high up to $500 \mathrm{kpa}[1]$.

\section{The structure of the exhaust gas turbocharger is introduced}

Figure 1 is the exhaust turbine supercharger assembly drawing. The composition of the turbocharger is mainly consists of three parts. Gas turbine housing, turbine shaft bearing body shell and air compressors. The turbine and impeller rotor rotating parts. The rotor assembly after formation as a whole. Turbine is located in the indoor exhaust machine work, the impeller is located in the indoor air compressor work, connecting shaft is made up of intermediate bearing.

The rotor is the only moving parts in the supercharger. Its rotation is entirely driven by engine 
exhaust emissions. To see its rotation efficiency is one of the key factors affecting supercharger turbo value. The factors affecting its rotation is determined by a number of aspects. One is the influence of engine exhaust emissions, engine configuration supercharger is usually based on the engine power lines.

Engine displacement is the only drive rotor rotational energy. The second influence of rotor rotational speed is waste gas flow rate. Affect the exhaust gas flow velocity is turbine housing transformation way of exhaust gas velocity. The passage of the turbine shell form and the flow area of laryngeal orifice (nozzle ring) finally decided the exhaust turbine blade force into the exhaust machine speed below.

The rotation of the rotor speed is influenced by the following factors. The manufacturing precision of the rotor effect the precision of rotor here mainly reflects in the assembly of the rotor's overall precision of the rotor. Embodied in the rotor rotation accuracy is the rotor dynamic balance accuracy[2]. The machining precision of rotor shaft and rotor with the precision of parts. The rotor turning resistance moment includes the friction and the gas flow resistance moment. Frictional resistance moment of resistance moment produced by viscosity of lubricating oil and gas friction resistance moment the role of the two. The gas flow resistance torque acting on blades produced by gas accelerated force produced by the moment. The drag torque will reduce the speed of the turbine shaft.

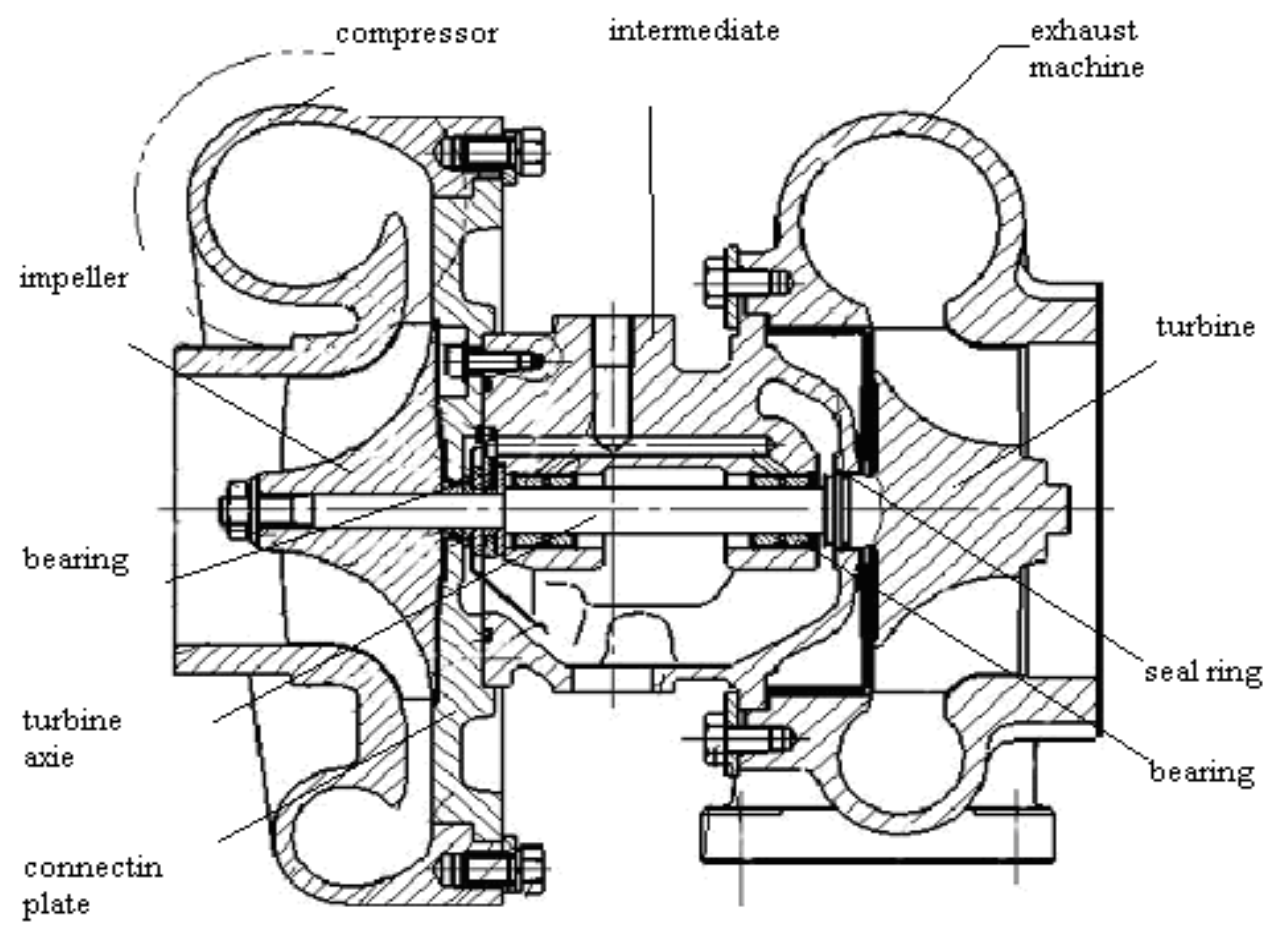

Figure 1 exhaust turbocharger assembly

\section{Exhaust machine working cavity flow change}

According to the momentum theorem of particle system, namely the type of $n$ to the number of particles within particle system, mi for the quality of the ith a particle in particle system. Vi is the speed of this point, the momentum of the particle system is a vector. Momentum vector change with velocity vector direction. Thus the momentum of the gas on the impact of the turbine is related with the speed of the gas direction.

Working for air exhaust machine shell change is the biggest influence factors of the engine exhaust emissions. Decide the quality of the momentum $\mathrm{m}$ engine emissions. Is temperature of exhaust gas in through the exhaust pipe of the loss. Temperature and decreased with the extension of exhaust line. Under the condition of closed pipeline gas flow loss was negligible. The velocity of the gas flow area and the related only. Gas in pipe flows when the velocity is constant. When gas passage into the rotation of the turbine cylinder gas velocity, pressure increases. Due to the rotation 
of the turbine housing channel from big to small, is the area of the gas in the channel of speed change is from low to high. Work in the rotation of the turbine housing channel and impeller circumferential direction of the open cavity with annular slot. Annular slot as the nozzle of the airflow speed in order to improve the air flow into the working speed of the impeller. Of working in the six exhaust machine shell gas pressure can through the nozzle ring into kinetic energy.

On the structure design of nozzle ring exports are the biggest diameter of impeller blades. The direction of gas flow is dispersed through space through the leaf. Due to the two blades on flow length difference formation on the surface of the surface pressure difference. So the outer surface of the blade of gas flow rate is fast, the surface gas flow velocity is slow. The front of the impeller blade toward the outer surface. Due to the flow direction of air flow is distributed. Promote the airflow along the impeller blade rotation impeller rotation. Parallel to the impeller shaft to the gas flow rate on the blade surface of the two are equal, the effect of this part of the air does not affect the rotation of the impeller. But if the air flow caused by the uneven flow along the impeller shaft to the cyclone prevents the rotation of the impeller.

The width of the nozzle ring opening on the ordinary type of supercharger turbo shells are fixed. Engine exhaust decided how many nozzle ring export gas velocity. At the same time also determines the rotational speed of the turbine. Engine exhaust gas energy is the only drive a turbine. So in the use of the energy of exhaust gas should be improve velocity as the main method of the design.

\section{The influence of exhaust gas adjusting device for air changes}

Figure 2 is a rotary vane type gas regulator. Shown in figure 2 is a kind of changing inlet opening size of exhaust gas by rotating impeller adjusting device. In order to solve the turbocharger in internal combustion engine speed turbo lag and the low pressurization value. Using waste gas inlet regulating control device. [2]

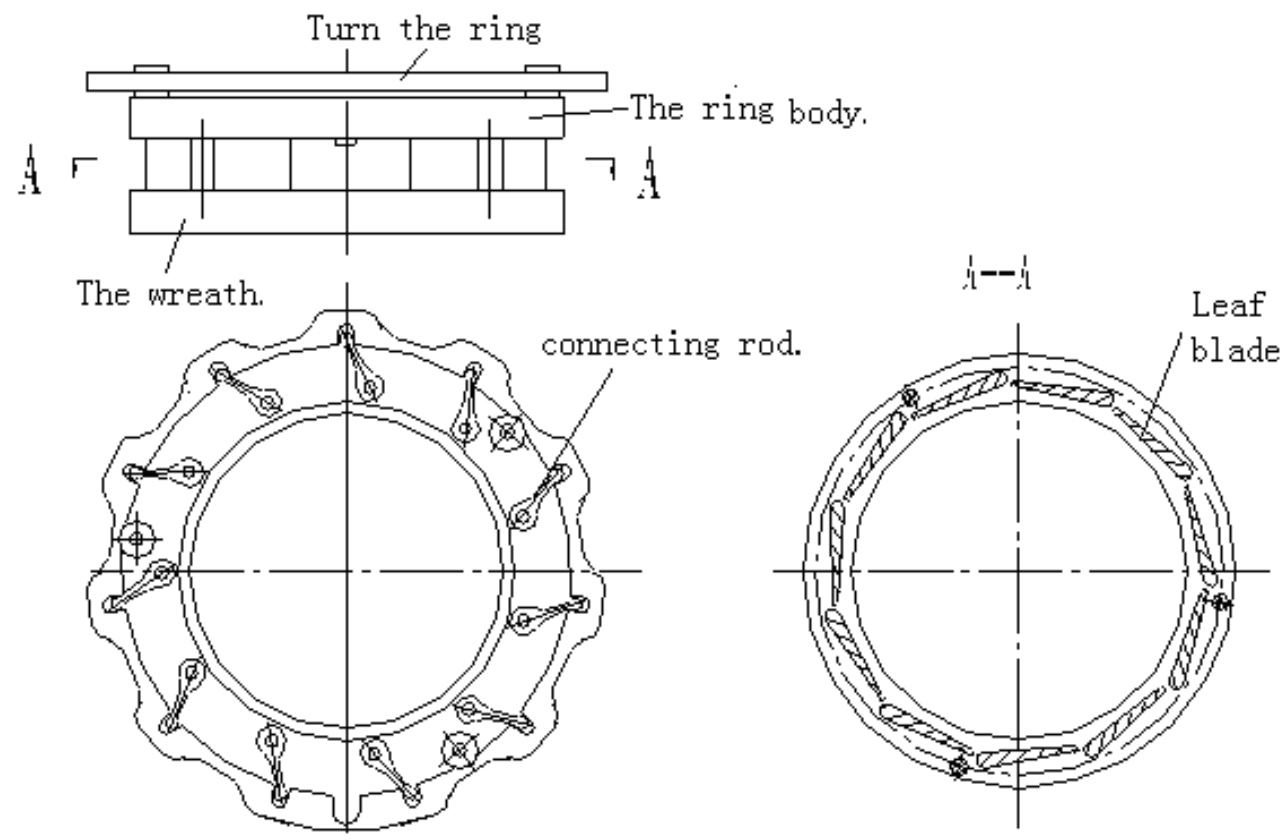

Figure 2. Rotary vane type gas regulator

Turbo air exhaust gas regulator consists of rotating ring, blade, ring on the body, the wreath. Turn the ring is used to drive blade rotation[3]. A - is shown in A view to exhaust gas regulator closed. The position of the minimal blade openings. Turn the ring is connected to the blade connecting rod. Turning ring rotates the blades connecting rod drives the blade rotation. Blade Angle changes in the form of opening the adjust exhaust air inflow and inlet velocity. Thus to implement the machine exhaust waste gas into the impeller inlet air flow control. The turbine speed control.

The opening of the blade Angle with the rotating ring rotation changes. The direction of the airflow into the impeller chamber work change with the direction of the blade. The direction of 
fluid flow changes affect the direction of the momentum. The exhaust gas regulator airflow direction changes impact on the efficiency of the impeller rotation test of the work is not enough. Testing can be illustrated by detecting the impeller speed change values on the influence of airflow direction on the impeller speed. This work needs to be further developed.

Exhaust gas in the regulator of the opening Angle of the blade under the action of change speed changed. According to the principle of gas flow continuously. Flow rate is equal to the velocity of flow area multiplied by. Under the condition of flow is constant gas flow rate is inversely proportional to the flow cross-section area[4]. Exhaust gas regulator is just the way using the flow cross-section area change control the velocity of the gas.

As shown in figure 2 gas regulator can change the exhaust gas flow velocity and direction. Rotary vane gas flow direction when opening the smallest along the turbine blade tangential into the big end. This is gas turbine blades of propulsive efficiency is highest. With the increase of regulator rotary vane opening airflow direction. Gas point of turbine blades is scattered. The gas drops to promote the efficiency of the turbine blades. But due to the increased amount of regulator blade opening is increased with the increase of engine exhaust emissions increased. The speed of the turbine blade increased with the increase of the volume increase. So the waste gas regulator is to improve the working condition of low runtime supercharger turbo engine speed of a method[5].

\section{Conclusion}

The influencing factors of turbocharger turbine shaft rotational speed is the engine exhaust emissions. General engine in the configuration of the supercharger is according to the line power of the engine. Engine displacement is the only drive rotor rotational energy. The second influence of rotor rotational speed is waste gas flow rate. Affect the exhaust gas flow velocity is turbine housing transformation way of exhaust gas velocity. The passage of the turbine shell form and the flow area of laryngeal orifice (nozzle ring) finally decided the exhaust turbine blade force into the exhaust machine speed below. The third factor is the influence of the manufacturing precision of the rotor and assembly accuracy.

In engine displacement under the same conditions for improvement of the turbine rotational speed factor is into the working of the kinetic energy of the gas turbine and the direction of airflow. Flow area of turbine working chamber inlet decided to gas velocity. But the flow area of turbine working chamber inlet can't decide the direction of gas flow. Method to control the turbocharger turbine shaft rotational speed is using exhaust gas conditioning improve turbine inlet gas flow speed and direction.

\section{References}

[1] Su-ying Xu, Li-jun Qiu, 2011 2nd International Conference on Mechanic Automation and Control Engineering,MACE2011-proceeding,p909-911.

[2] Ke-long Yu, Li-jun Qiu, 2011 2nd International Conference on Mechanic Automation and Control Engineering,MACE2011-proceeding,p906-908.

[3] Su-ying Xu, Li-jun Qiu, Applied Mechanics and Materrials ,v 164,2012,p375-378.

[4]Li-jun Qiu,Jia Yang,Su-ying Xu, Advanced Materials Research Vols, 308-310(2011), p1333-1336.

[5] Li-jun Qiu, Xu Suying,Applied Mechanics and Materrials,v251(2013),p97-100. 